U.K., Vol. XLI), and also in an article on the Anatomy and Physiology of Accommodation in Mammalia (Trans. Ophthal. Soc. U.K., Vol. XLVI), will be found ample evidence to refute every one of his reasons for the conclusion that from its nature, structure, position, etc., etc., Descemet's Membrane should be regarded as an anterior tendon of the Ciliary Muscle.

Yours faithfully,

Nottingham.

THOMSON HENDERSON.

December 2, 1933.

\title{
THREADING OF NEEDLES
}

To the Editors of THE BRItish Journal OF OPHTHALMOLOGY.

SIRS,-The threading of number one plaited advancement silk on a number four curved needle requires some dexterity, especially after the silk has been boiled or during an operation. But by a method described by Dr. Poth, of San Francisco, in the Jl. A mer. Med. Assoc. (February 25, 1933), the matter becomes simplicity itself. The original description is modified to suit the ophthalmic surgeon.

Take a piece of wire used for keeping patent the needle of a hypodermic syringe. Make it into a loop and grasp the two ends with an artery forceps. Pass a piece of silk through the loop and pull tight to shape the end of the wire so that it will readily pass through the eye of the needle. Remove the silk and pass the doubled wire through the eye of the needle or through the eyes of the several needles. Pass the silk through the loop of the wire and draw it through the needle or needles, thus threading them. The silk then can be cut into proper lengths.

If a wire loop as described is available on the instrument table, with a needle threaded, a suture which has broken between the muscle and the needle can be instantly rethreaded.

Yours truly,

A. F. MacCallan. 